\title{
Synthesis of N-(9-Acridinyl)maleimide, a Fluorometrical Reagent for Thiol Compounds
}

\author{
Yasunori Nara and Katura Tuzimura \\ Department of Food Chemistry, Faculty of Agriculture, \\ Tohoku University, Sendai \\ Recejved October 21, 1977
}

\begin{abstract}
The authors have reported ${ }^{1)}$ a new maleimide type fluorescent thiol reagent, $\mathrm{N}$-(9-acridinyl)maleimide (NAM). In this paper the syntheses of NAM and its coupling products with thiol compounds are presented. NAM was synthesized from 9-aminoacridine and maleic anhydride through dehydratic cyclization in polyphosphoric acid. NAM showed no substantial fluorescence but its coupling products with thiol compounds exhibited strong blue fluorescence. Application of NAM for the fluorometrical analysis of cysteine and glutathione are suggested.
\end{abstract}

Since Friedman (1952) ${ }^{2}$ developed N-ethylmaleimide which reacts rapidly and specifically with thiol groups under a mild condition, several derivatives have been synthesized for colorimetric $^{3 /}$ and fluorometric ${ }^{4)}$ purposes and also for the modification of protein. ${ }^{5)} \mathrm{N}-(9-$ Acridinyl)maleimide, ${ }^{11}$ originally synthesized by us, is one of the maleimide type reagents which has faint fluorescence but gives strong blue fluorescence by the reaction with thiol compounds. In the present paper, the syntheses of the reagent and its thiol derivatives are described.

\section{RESULTS AND DISCUSSION}

\section{Synthesis of NAM and NAS}

NAM (III) was synthesized through the reactions shown in Scheme 1. The scheme followed the general procedure of the synthesis of $\mathrm{N}$-substituted aromatic maleimides. Aminoacridine (I) and maleic anhydride were reacted to produce $\mathrm{N}$-(9-acridinyl)maleamic acid (II), which was transformed to NAM (III) by dehydratic cyclization with polyphosphoric acid.

Condensation reaction of (I) and maleic anhydride proceeded quantitatively. How-

Abbreviation: NAM, N-(9-acridiny1)maleimide; NAS, N-(9-acridinyl)succinimide; NAM-Cys, NAM-Et and NAM-GSH, coupling compouns of NAM with cysteine, ethanethiol and glutathione, respectively. ever, the yield of the following dehydratic cyclization was only $25.7 \%$. The cyclization with acetic anhydride-sodium acetate was unsuccessful; the yield was only $6 \%$. NAS was synthethized by a similar manner, using succinic anhydride instead of maleic anhydride. The yield was $50.2 \%$.

The spectrometric behavior of NAM and NAS

The IR, PMR, MS and UV spectra of NAM and NAS are shown in Figs. $1 \sim 4$. Discrimination of the IR spectra of NAM and NAS (Fig. 1) was not clear, although absorptions at $3080,1715,1635(w)$ and $850 \mathrm{~cm}^{-1}$ of NAM seemed to correspond to maleimide ring, and absorptions at 1780,1705 and $1175 \mathrm{~cm}^{-1}$ of NAS seemed to correspond to succinimide ring. ${ }^{7}$ On the other hand, discrimination of the PMR spectra (Fig. 2) was distinct. The spectrum of NAM revealed a singlet of 2 protons at $\delta 7.28 \mathrm{ppm}$ which was assignable to the double bond protons of maleimide ring. The spectrum of NAS revealed a singlet of 4 protons at $\delta 3.65 \mathrm{ppm}$ corresponding to the methylene protons of succinimide ring. ${ }^{6>}$ The mass spectra (Fig. 3) of NAM and NAS showed large molecular peaks as base peaks. The UV spectra (Fig. 4) of NAM and NAS overlapped. The absorption maximum was $362 \mathrm{~nm}$, and molecular absorption coefficient was 14,000 . 


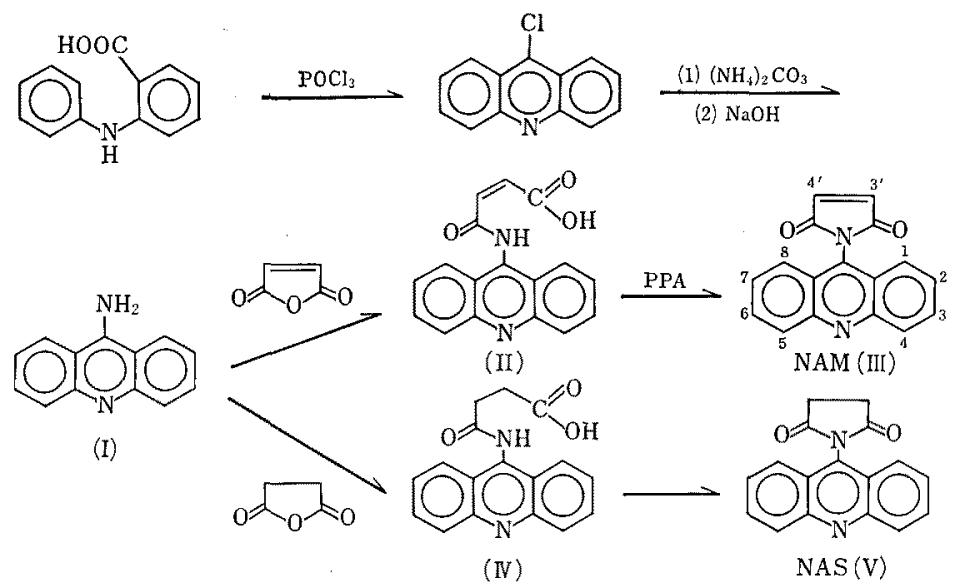

ScHeme 1. Outline of Synthesis of NAM and NAS.

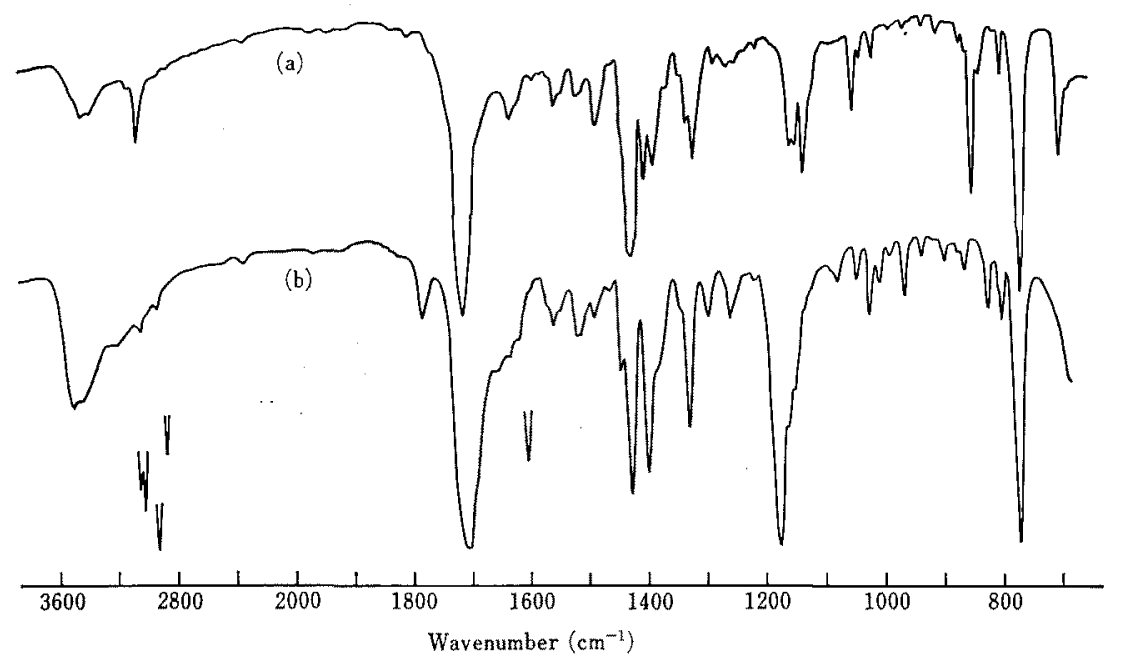

FIG. 1. Infrared Spectra of NAM (a) and NAS (b) ( $\mathrm{KBr}_{2}^{-}$disk).

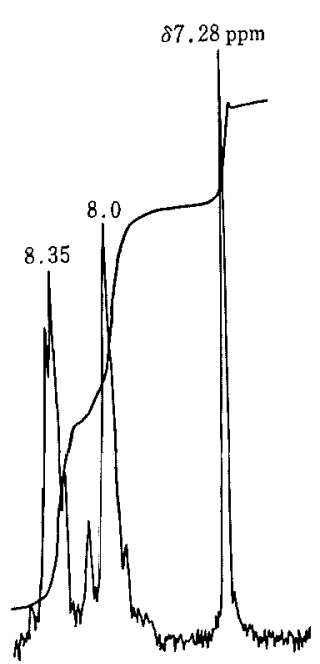

FIG. 2. PMR Spectrum of NAM.
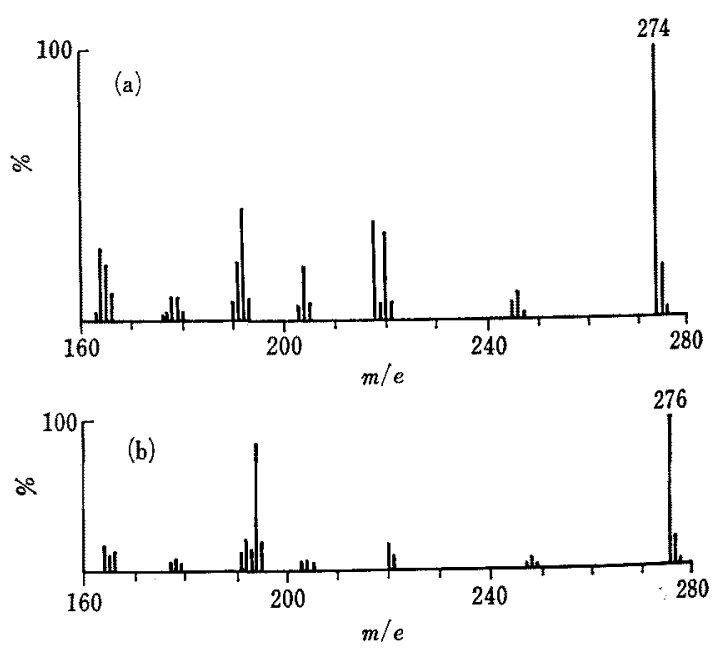

Fig. 3. Mass Spectra of NAM (a) and NAS (b). Electron-impact Ionization. JEOL JMS 06. 


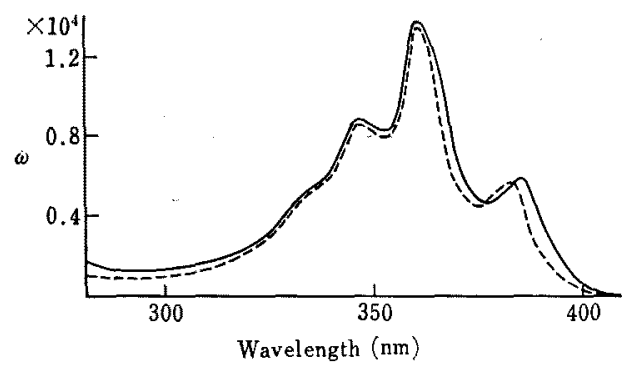

FIG. 4. UV Absorption Spectra of NAM and NAS. Solvent: dioxane, NAM, - _ ; NAS, -...-....

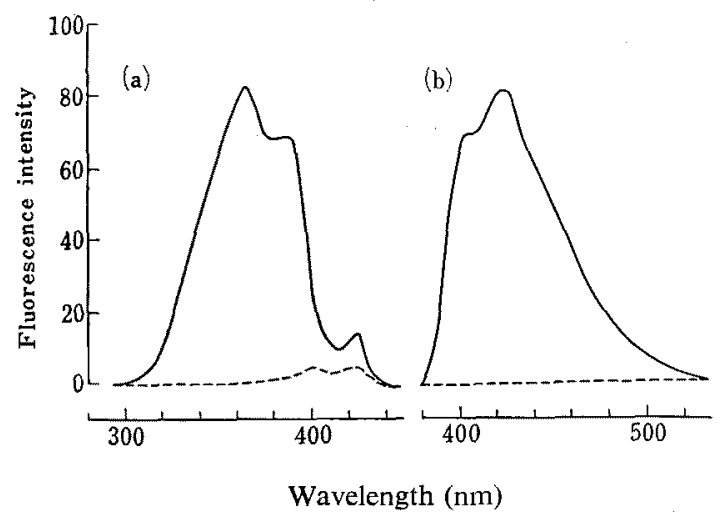

FIG. 5. Fluorescence Spectra of a Reaction Mixture of NAM with Cysteine.

Acetone solution of $0.1 \mathrm{mM}$ NAM $(2.0 \mathrm{ml})$ was mixed with $\mathrm{HCl}-\mathrm{CH}_{3} \mathrm{COONa}$ buffer $(0.5 \mathrm{M}, \mathrm{pH} 3.5)$ solution of $0.33 \mathrm{~mm}$ cysteine $(3.0 \mathrm{ml})$. After $30 \mathrm{~min}$, fluorescence excitation (a) and emission (b) spectra were measured at $426 \mathrm{~nm}$ as the monitoring wavelength and at $360 \mathrm{~nm}$ as the excitation wavelength. Dotted lines indicates the spectra of the reaction mixture with no cysteine.
The fluorescence behavior of NAM was similar to that of the maleimide derivatives presented by Kanaoka et al. ${ }^{4}$ ) Namely these maleimide derivatives were practically nonfluorescent but the addition products with thiol compounds had strong fluorescence. The fluorescence spectra of the reaction mixture of NAM with cysteine is shown in Fig. 5. The excitation maximum was $360 \mathrm{~nm}$ and the emission maximum was $426 \mathrm{~nm}$.

\section{Coupling compounds of NAM with thiols}

Coupling compounds of NAM with ethanethiol, cysteine and glutathione were synthesized as described in EXPERIMENTAL. By coupling with ethanethiol or glutathione only one compound was obtained, respectively. But by coupling with cysteine, two compounds, NAMCys I and II, were obtained.

The IR spectrum of NAM-Et resembled that of NAS, except a slight short wave shift (10 $15 \mathrm{~cm}^{-1}$ ) of $\mathrm{CO}$ peak and the appearance of $\mathrm{CH}$ stretching at 2940 and $2980 \mathrm{~cm}^{-1}$. The IR spectrum of NAM-Acetylcys (the coupling product of NAM and N-acetyl cysteine) is illustrated in Fig. 6. The spectrum was almost the same as that of NAS, except the appearance of a medium peak at $1655 \mathrm{~cm}^{-1}$ derived from amino acid moiety. The IR spectra of NAMCys I and NAM-GSH resembled that of NAMAcetylcys. But the IR spectrum of NAM-Cys II was different. A strong peak at $1660 \mathrm{~cm}^{-1}$ appeared and the peak at $1780 \mathrm{~cm}^{-1}$ disap-

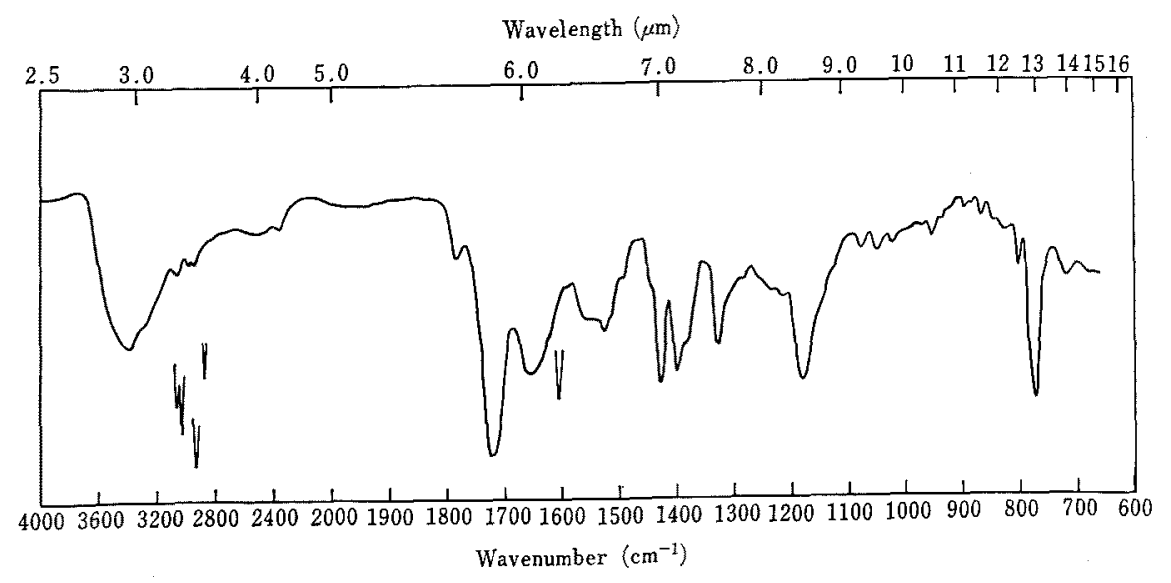

FiG. 6. IR Spectrum of NAM-Acetylcys. 


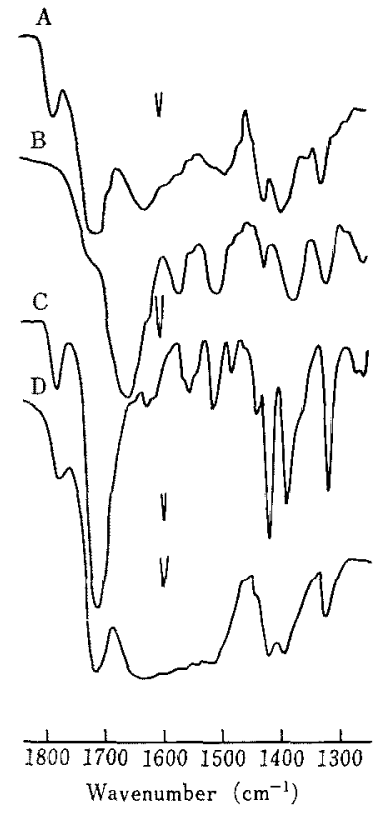

Fia. 7. Carbonyl Region of Infrared Spectra of NAM Derivatives.

A, NAM-Cys-I; B, NAM-Cys-II; C, NAM-Et; D, NAM-GSH.

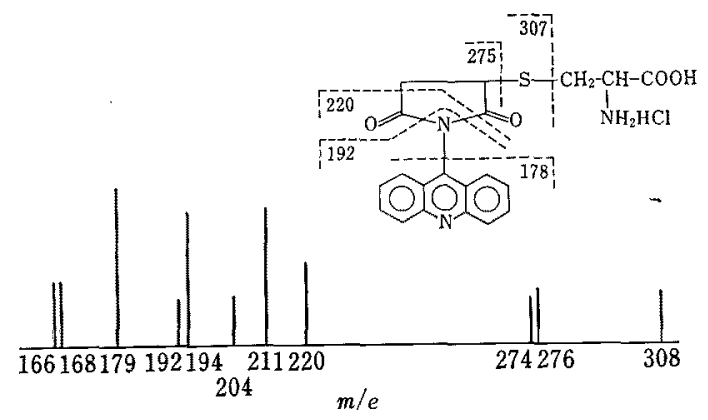

FiG. 8. Mass Spectrum of NAM-Cys-I.

peared. The strong peak at $1715 \mathrm{~cm}^{-1}$ and the medium peak at $1630 \mathrm{~cm}^{-1}$ seemed to disappear or to dimish by being hidden by the strong 1660 peak. A part of these spectra are shown in Fig. 7. The ninhydrin test was positive with NAM-Cys I and negative with NAM-Cys II, indicating the disappearance of the free amino group in the latter. The mass spectrum of NAM-Cys I (Fig. 8) showed peaks at $m / e 308(307+\mathrm{H}), 276(275+\mathrm{H})$ and 274 $\left(308-\mathrm{H}_{2} \mathrm{~S}\right)$ indicating the presence of succinimide ring. From these facts the reaction of

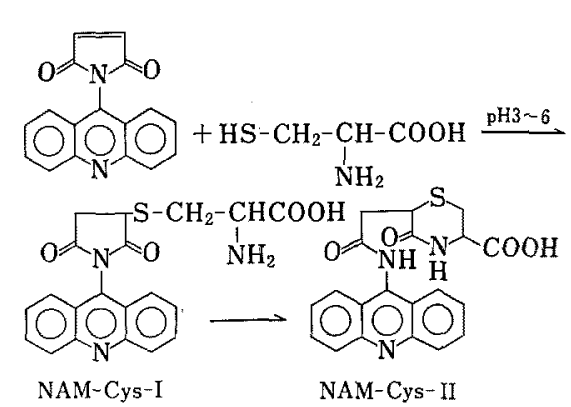

SCHEME 2. Reaction of NAM with Cysteine.

NAM with cysteine might probably be illustrated as Scheme 2.

\section{Stability of NAM-thiol coupling compounds}

The fluorescence intensity of NAM-Et in a buffer solution was stable more than $2 \mathrm{hr}$ when $\mathrm{pH}$ was $3.5 \sim 7.0$ and then gradually decreased. At pH more than 8.0 the decrease took place more rapidly by increasing alkalinity.

The fluorescence intensity of NAM-Cys-I was stable at $\mathrm{pH} 2 \sim 4$ and $9 \sim 10$, although the intensity was stronger under the latter condition. In the solution of pH $5 \sim 8$, the intensity gradually increased within $1 \sim 2 \mathrm{hr}$ from the acid level to the intensity level of the alkaline condition. The UV-absorption and fluorescence spectra of the solution of NAMCys-I and II were different from each other in acid and neutral solutions. But in an alkaline

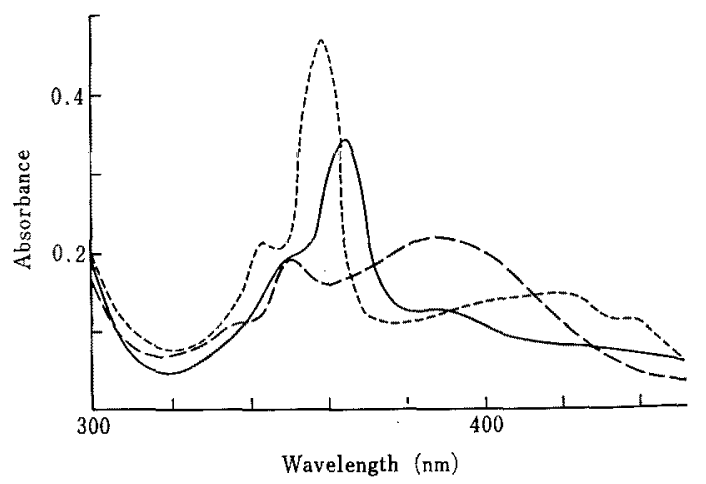

FIG. 9. UV Absorption Spectra of NAM-Cys.

$\longrightarrow$, NAM-Cys-I in pH 3.5, 0.5 M HCl-AcONa buffer; ----, NAM-Cys-II in pH 3.5, $0.5 \mathrm{M} \mathrm{HCl-AcONa}$ buffer; - - , NAM-Cys-I and II in pH $12.0,0.25 \mathrm{M}$ phosphate buffer. Concentration, $2.4 \times 10^{-7} \mathrm{M}$. 


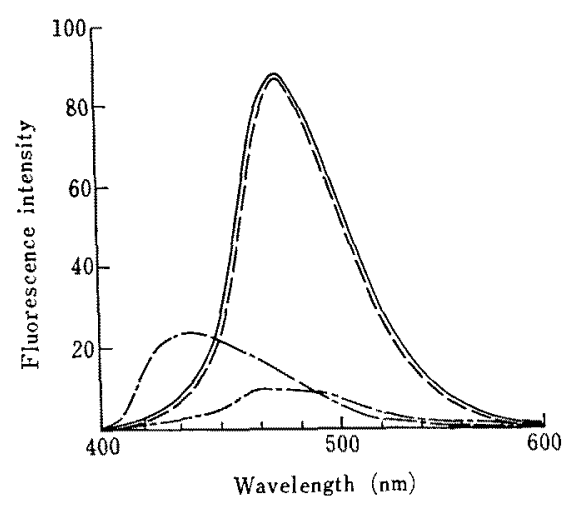

FIG. 10. Fluorescence Spectra of NAM-Cys.

NAM-Cys-I: $\mathrm{pH} 12,-\cdots-$;H $3.5, \cdots-$. NAM-CysII: $\mathrm{pH} 12, \ldots ; \mathrm{pH} 3.5, \ldots$. Concentration: $4.4 \times 10^{-6} \mathrm{M}$.

solution ( $\mathrm{pH} \mathrm{12)}$ both compounds showed identical absorption and fluorescence spectra. These differed from the spectra in the acid and neutral solutions (Figs. 9, 10). In the alkaline solution, the ninhydrin test was negative. The structural change of the product with cysteine has been reported in the case of other maleimide fluorescent derivatives by Kanaoka et al. ${ }^{4}$ The fluorescence spectrum of the reaction mixture presented in Fig. 5 was identical with that of NAM-Cys-I. Care must be taken for $\mathrm{pH}$, when NAM is applied to the analysis of cysteine.

\section{EXPERIMENTAL}

\section{Synthesis of NAM}

9-Aminoacridine (I) was prepared from $\mathrm{N}$-phenylanthranilic acid by the method of Albert et al. ${ }^{\mathrm{e})}$ (Scheme 1), and was recrystallized from acetone. Compound $\mathrm{I}(5.5 \mathrm{~g})$ and maleic anhydride $(20 \mathrm{~g})$ were dissolved each into absolute acetone $(420 \mathrm{ml}$ and $80 \mathrm{ml}$ respectively) and mixed. The mixture was stirred at room temperature for $4 \mathrm{hr}$. The resulting yellow precipitate of $\mathrm{N}$-(9-acridinyl)maleamic acid (II) was collected and dried over $\mathrm{P}_{2} \mathrm{O}_{5}$. Yield: $8 \mathrm{~g}, 96 \%$ from (1), $\mathrm{mp} 152^{\circ} \mathrm{C}$.

Compound II $(4 \mathrm{~g})$ was mixed with $40 \mathrm{~g}$ of polyphosphoric acid. The viscous mixture was heated at $135^{\circ} \mathrm{C}$ for $1 \mathrm{hr}$. After cooling to room temperature the reaction mixture was poured on ice. After the precipitate was removed by filtration, the filtrate was neutralized with sodium hydrogen carbonate powder. The resulting precipitate was collected, washed with water and dried. By recrystallization from acetone, TLC-pure NAM was obtained. Yield: $1 \mathrm{~g}(25.7 \%$ from II), decomp $248^{\circ} \mathrm{C}$, Anal. found: C, $74.29 ; \mathrm{H}, 3.57$; $\mathrm{N}, 10.08 \%$, calcd. for $\mathrm{C}_{17} \mathrm{H}_{10} \mathrm{~N}_{2} \mathrm{O}_{2}: \mathrm{C}, 74.44 ; \mathrm{H}, 3.68$; N, 10.21\%. UV (Fig. 4): $\varepsilon_{382}$ 14,000. IR (Fig. 1): $3450 \mathrm{~cm}^{-1}$ (broad), $3050(\mathrm{~m}), 1715(\mathrm{~s}), 1635(\mathrm{~m})$, $1560(\mathrm{w}), 1520(\mathrm{w}), 1490(\mathrm{w}), 1430(\mathrm{~s}), 1410(\mathrm{~m}), 1390$ (m), $1320(\mathrm{~m}), 1150(\mathrm{~m}), 1130(\mathrm{~m}), 1050(\mathrm{w}), 1020(\mathrm{w})$, $850(\mathrm{~m}), 770(\mathrm{~s}), 710(\mathrm{~m}) . \quad$ PMR (Fig. 2): $\delta 7.28 \mathrm{ppm}$ $\left(\mathrm{H}-3^{\prime}, 4^{\prime}\right) ; 8.0(\mathrm{H}-2,3,6,7) ; 8.35$ (H-1,4,5,8). MS (Fig. 3): m/e $274(100 \%), 192(41), 218(36), 220(32), 164$ (22), $204(20)$.

\section{Synthesis of NAS}

NAS (V) was synthesized by a manner similar to that for NAM, except succinic anhydride was used in place of maleic anhydride. Yield: $1 \mathrm{~g}(50.2 \%$ from IV), decomp. $270^{\circ} \mathrm{C}$. UV: $\varepsilon_{362} 14,000$. IR: $3450 \mathrm{~cm}^{-1}$ (broad), 3050?, 2950?, $1780(\mathrm{w}), 1715(\mathrm{~s}), 1560(\mathrm{w})$, $1520(\mathrm{w}), 1490(\mathrm{w}), 1430(\mathrm{~m}), 1400(\mathrm{~m}), 1330(\mathrm{~m})$, $1300(\mathrm{~m}), 1260(\mathrm{w}), 1180(\mathrm{~s}), 1020(\mathrm{w}), 960(\mathrm{w}), 770(\mathrm{~s})$. PMR: $\delta 3.65$ ppm (4 protons, H-3', $\left.4^{\prime}\right) ; 8.28(\mathrm{H}-2,3,6,7)$; $8.53(\mathrm{H}-1,4,5,8)$. MS: $m / e 276(100 \%), 194(87)$, $220(20)$.

\section{Synthesis of $S-[N-(9$-acridinyl)succinimide]ethanthiol (NAM-Et)}

To a solution of NAM (140 mg, $0.51 \mathrm{mmol}$ ) in $60 \mathrm{ml}$ of acetone, $0.4 \mathrm{ml}(0.54 \mathrm{mmol})$ of ethanethiol and $10 \mathrm{ml}$ of water were added. The mixture was allowed to react for $30 \mathrm{~min}$ at room temperature, and then acetone was evaporated. The precipitate was collected by filtration and washed with water. Yield: $170 \mathrm{mg}$, $99.1 \%$. The crude preparate was purified by silica gel column chromatography (eluent; benzene: ethyl acetate, $3: 1)$. Recrystallization was made from ether-petroleum ether. This preparation was TLC-pure. Yield: $155 \mathrm{mg}, \mathrm{mp} 106 \sim 107^{\circ} \mathrm{C}$. Anal. found: C, $68.08 ; \mathrm{H}$, $4.88 ; \mathrm{N}, 8.18 \%$, calcd. for $\mathrm{C}_{10} \mathrm{H}_{18} \mathrm{~N}_{2} \mathrm{O}_{2} \mathrm{~S}: \mathrm{C}, 67.84$; $\mathrm{H}, 4.79 ; \mathrm{N}, 8.33 \%$. UV: $\hat{\varepsilon}_{364} 1.6 \times 10^{4}(\mathrm{pH} 3.5), \varepsilon_{360}$ $1.2 \times 10^{4}\left(\mathrm{pH} \mathrm{10.0)}\right.$. Fluor.: $E_{\max } 437 \mathrm{~nm}(\mathrm{pH} 8.0)$. IR: 3420 (broad), 3050 (w), $2980(w), 2940(w), 1780$ $(w), 1720(s), 1630(w), 1560(w) 1520(w) 1490(w)$, $1425(\mathrm{~m}), 1395(\mathrm{~m}), 1325(\mathrm{~m}), 1175(\mathrm{~m}), 770(\mathrm{~m})$.

\section{Synthesis of $S$-[N-(9-acridinyl)succinimide $]$ cysteine (NAM-Cys)}

To a solution of NAM $(137 \mathrm{mg}, 0.5 \mathrm{mmcl})$ in $50 \mathrm{ml}$ of acetone, cysteine in $2 \mathrm{ml}$ of water (cysteine hydrochloride $95 \mathrm{mg}, 0.6 \mathrm{mmol}$ ) was added. After $10 \mathrm{~min}$ of reaction, most of acetone was removed by evaporation in vacuo below $30^{\circ} \mathrm{C}$. The residual aqueous solution was allowed to stand in a refrigerator for $3 \mathrm{hr}$. The precipitated crystal was collected by filtration, washed with water and dried over $\mathrm{P}_{2} \mathrm{O}_{5}$. This S-[N- $(9-$ acridinyl)succinimide]cysteine-I was conveniently ab-

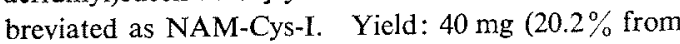


III), mp $159 \sim 161^{\circ} \mathrm{C}$. Elementary analysis did not agree well with calculation. But the IR spectrum agreed well with that of NAM-Acetylcys (Fig. 6). UV: $\varepsilon_{958} 2.0 \times 10^{4}(\mathrm{pH} 12.0)$. IR: $3400 \sim 3000$ (broad), $1780(\mathrm{w}), 1710(\mathrm{~s}), 1630(\mathrm{~m}), 1490(\mathrm{w}), 1425(\mathrm{~m}), 1390$ (m), $1325(\mathrm{w}), 1170(\mathrm{~s}), 770(\mathrm{~s}) \mathrm{cm}^{-1}$. MS: no $\mathrm{M}^{+}$ peak, $m / e 179(100), 194(84), 211(82), 220(41), 166(41)$, 168 (41), 276 (35), 308 (32), 204 (29), 192 (29), 247 (27).

The filtrate and washings were combined and allowed to stand in a refrigerator overnight. Another crystals were obtained (55 $\mathrm{mg}, 26.6 \%$ from III) which were recrystallized from diluted $\mathrm{HCl}$. This compound was abbreviated as NAM-Cys-II. Decomp. $203 \sim 204^{\circ} \mathrm{C}$. Elementary analysis did not agree well with calcd. UV: $\varepsilon_{958} 2.0 \times 10^{4}(\mathrm{pH} 12.0)$. IR: $3380,3240,1660(\mathrm{~s})$, $1570(\mathrm{~m}), 1510(\mathrm{~m}), 1425(\mathrm{w}), 1380(\mathrm{~m}), 1320(\mathrm{~m}), 1260$ $(w), 1230(w), 1190(w), 1160(w), 780(m)$.

Synthesis of $S-[N-(9$-acridinyl)succinimide $]-N$-acetylcysteine (NAM-Acetylcys)

To $100 \mathrm{ml}$ of an acetone solution of NAM $(164 \mathrm{mg}$, $0.6 \mathrm{mmol}), 8 \mathrm{ml}$ of an aqueous solution of N-acetylcysteine $(163 \mathrm{mg}, 1.0 \mathrm{mmol})$ was added. After the reaction of $20 \mathrm{~min}$, acetone was evaporated in vacuo. The resulting precipitate was collected and was recrystallized from hot $95 \%$ ethanol. Yield: $210 \mathrm{mg}$, $90 \%$. mp $150 \sim 152^{\circ} \mathrm{C}$. Anal. found: C, $58.44 ; \mathrm{H}$, $4.11 ; \mathrm{N}, 9.41 \%$. Calcd. for $\mathrm{C}_{22} \mathrm{H}_{10} \mathrm{~N}_{3} \mathrm{O}_{5} \mathrm{~S} \cdot \mathrm{H}_{2} \mathrm{O}$ : C, $58.01 ; \mathrm{H}, 4.20 ; \mathrm{N}, 9.23 \%$. UV: $\varepsilon_{862} 1.4 \times 10^{4}(90 \%$ EtOH). IR: 3400 (broad), $3050(w), 2980(w), 2940$ $(w), 1780(w), 1720(\mathrm{~s}), 1650(\mathrm{~m}), 1525(\mathrm{~m}), 1430(\mathrm{~m})$, $1400(\mathrm{~m}), 1325(\mathrm{~m}), 1180(\mathrm{~m}), 770(\mathrm{~m})$.
Synthesis of $S-[N$-(9-acridinyl)succinimide $]$-glutathione $(N A M \cdot G S H)$

To $50 \mathrm{ml}$ of an acetone solution of NAM $(137 \mathrm{mg}$, $0.5 \mathrm{mmol})$, a solution of glutathione $(160 \mathrm{mg}, 0.52 \mathrm{mmol}$, in $0.2 \mathrm{M} \mathrm{pH} 3.5 \mathrm{HCl}-\mathrm{CH}_{3} \mathrm{COONa}$ buffer) was added. After $10 \mathrm{~min}$ of reaction, acetone was evaporated. The residual solution was purified by silica gel column chromatography (eluent; water). The fluorescent fraction was collected and was lyophilized. Yield: $110 \mathrm{mg}, 80.3 \%, \mathrm{mp} 166.5 \sim 169.5^{\circ} \mathrm{C}$.

Acknowledgement. We indebted to Mr. Hiroaki Takahashi for the preparation of this manuscript.

\section{REFERENCES}

1) T. Nara and K. Tuzimura, Bunseki Kagaku (Japan Analyst), 22, 451 (1973).

2) E. Friedman, Biochim. Biophys. Acta, 9, 65 (1952).

3) A. Witter and H. Tuppy, ibid., 45, 429 (1960).

4) Y. Kanaoka, M. Machida, K. Ando and T. Sekine, ibid., 207, 269 (1970).

5) T. Ohyashiki, Y. Kanaoka and T. Sekine, ibid., 420, 27 (1976).

6) A. Albert and B. B. Richie, "Org. Syn.," Collect, Vol. 3, ed. by E. C. Horning, John Wiley and Sons, Inc., 1955, p. 53.

7) J. G. Grasseli and W. M. Ritchey, "Atlas of Spectral Data and Physical Constants for Organic Chemistry," Vol. IV, 2nd ed. C. R. C. Press Inc., 1975 , p. 550. 